\title{
Use of fitness to improve students' physical qualities
}

\author{
Sergey Yekimov ${ }^{1, *}$, Svitlana Pilova ${ }^{2}$, Iryna Panasiuk ${ }^{3}$, Sergii Galiuza ${ }^{4}$, and Vlada Bilohur ${ }^{5}$ \\ ${ }^{1}$ Publishing House "Education and Science" s.r.o., Olstynska 607/1, Praha 8, 18100, Czech Republic \\ ${ }^{2}$ Odessa National Maritime University, Odessa, Ukraine \\ ${ }^{3}$ National Polytechnic University, Odessa, Ukraine \\ ${ }^{4}$ Odessa national academy of telecommunications by O. S. Popov, Odessa, Ukraine \\ ${ }^{5}$ Melitopol State Pedagogical University named after Bohdan Khmelnytsky, Melitopol, Ukraine
}

\begin{abstract}
The rhythm and tempo of music has a beneficial impact on a person's desire to perform in unison movements. They can calm or excite the human nervous system and have a beneficial effect on the overall physical condition of the person. Regular fitness classes help to improve the mental and physical performance of students. Types and forms of fitness aerobics allow you to use an individual approach when choosing tools and methods in physical education lessons. In our opinion, the motor mode during fitness classes should correlate with the psychological and emotional state of the participants, as well as with their overall level of physical development. As a result of regular fitness classes in physical education classes, students improve the functioning of the musculoskeletal system and improve the development of skeletal muscles. The introduction of teaching in higher educational institutions of the training course "Valeology" in our opinion will allow students to gain important knowledge they need throughout their lives.
\end{abstract}

\section{Introduction}

Physical culture and sports are inextricably linked to a person's ability to acquire new skills necessary in their professional activities. In our opinion, efforts to preserve the state of personal health of students and the health of people around them should play an important role in the process of physical and moral education of students, as well as in the formation of a common culture of comprehensive personal development.

According to [1], an important problem that modern society requires from higher education is the training of specialists who, in addition to high professional skills, still have the required level of health, to maximize the disclosure of their creative and professional potentials.

According to [2], improving the quality of students ' training in higher education should provide not only for the availability of physical education classes in the curriculum, but also

*Corresponding author: 3701313@mail.ru 
for providing students with comprehensive knowledge about the influence of external factors on the state of human health.

The use of physical training classes for students, according to [3], should provide for the choice of the correct motor mode, which would correlate with the emotional and psychological state of the student and the overall level of his physical development.

According to [4,5], the dosed level of sports loads and their diverse nature make it possible to increase the level of physiological human reserves, as well as to avoid excessive overstrain of the human body during muscle work.

According to [6,7], an important indicator of the level of physical condition of a person is the state of the cardiovascular and respiratory systems of a person, as well as the level of overall physical performance of the entire human body.

Although the study of the problem of the influence of fitness on the human body has been studied for quite a long time, the question of the use of fitness in physical education classes has not yet been fully investigated. As part of this research work, we developed and put into practice a curriculum based on student fitness classes.

\section{Methods}

During the implementation of this study, we studied the impact of fitness classes on the process of improving the overall physical qualities of students. The classes took place during the training sessions on physical education with students of the Law Faculty of the Dnipro Polytechnic during the 2018/2019 academic year.

At the beginning of the study, we tested the level of general physical fitness of the trainees according to the following parameters:

1. Speed testing. It provided for students to run on the spot for 10 seconds and run at a distance of 60 meters for girls and run on the spot for 20 seconds and run at a distance of 100 meters for boys. In this test, we used pedometers to measure the number of steps taken by students per unit of time.

2. Measurement of the force of arms. In the process of measuring the strength of the hands, spring-loaded wrist dynamometers and exercises in the 24-kilogram kettlebell press, push-ups on the uneven bars and pull-ups on the crossbar were used for boys and girls. Hand strength dynamometry was performed for both hands for both boys and girls. In girls, the performance of the strength test involved measuring the number of exercises performed to bend the arms from the prone position for 2 minutes.

3. Measurement of coordination and dexterity. In order to test coordination and dexterity, special exercises were used, including movements with the right and left hand, exercises with a skipping rope and a ball for girls, as well as a shuttle run of 6x10 meters for boys.

4. Testing of mobility and flexibility in the joints. The measurement of joint mobility and flexibility was carried out by measuring the amplitude of their body movement in the subjects. In this test, the exercise was used to bend forward without bending the legs. The degree of flexibility in the vertebral column was measured by the distance from the floor to the fingertips at the maximum tilt of the subject. To determine the degree of mobility of the subjects of the knee compositions, squat exercises with hands behind the head were used. On the basis of this exercise was carried out to measure the degree of mobility at the knee. The final result was evaluated in points. The level of mobility in the students ' ankle joints was determined by the following method: the student was sitting on the floor, the feet of his feet were oriented perpendicular to the floor surface. Mobility was measured by the ability of the subject to stretch the toes of the feet, from the initial position to the maximum possible extension of the foot, the result of the measurements was evaluated according to the point system. 
5. Endurance testing. As an exercise for testing endurance, the 5000-meter run for boys and 2500-meter run for girls was used.

6. Measurement of bounce. Jumping ability was measured on the basis of the subjects ' jumps from the spot.

The authors give the indicators of physical qualities tests in Table 1:

Table 1. Indicators of assessment of physical qualities of students

\begin{tabular}{|c|c|c|c|c|c|c|c|c|}
\hline \multirow[t]{2}{*}{ № } & \multirow{2}{*}{$\begin{array}{c}\text { Types of } \\
\text { tests }\end{array}$} & \multirow{2}{*}{$\begin{array}{l}\text { Name of the } \\
\text { standard }\end{array}$} & \multirow[t]{2}{*}{ gender } & \multicolumn{5}{|c|}{ Points } \\
\hline & & & & 5 & 4 & 3 & 2 & 1 \\
\hline \multirow[t]{2}{*}{1} & \multirow[t]{2}{*}{ Speed Test } & \multirow{2}{*}{$\begin{array}{c}\text { Running at a } \\
\text { distance of } 100 \\
\text { meters (sec.) } \\
\text { Running at a } \\
\text { distance of } 60 \\
\text { meters (sec.) }\end{array}$} & $\mathrm{M}$ & 13.1 & 13.8 & 14.3 & 14.8 & 15.6 \\
\hline & & & $\mathrm{W}$ & 14.7 & 15.4 & 16.3 & 175 & 18.1 \\
\hline \multirow{4}{*}{2} & \multirow{4}{*}{ Strength Test } & $\begin{array}{c}\text { Pull- } \\
\text { up on a high } \\
\text { crossbar (times) }\end{array}$ & \multirow{3}{*}{ M } & 18 & 16 & 14 & 12 & 10 \\
\hline & & $\begin{array}{l}\text { Push-up on the } \\
\text { uneven bars } \\
\text { (times) }\end{array}$ & & 30 & 25 & 20 & 15 & 10 \\
\hline & & Bench press $(\mathrm{kg})$ & & 85 & 75 & 65 & 55 & 45 \\
\hline & & $\begin{array}{l}\text { Flexion and } \\
\text { extension of the } \\
\text { arms at the stop } \\
\text { lying down from } \\
\text { the gym bench } \\
\text { (times) }\end{array}$ & W & 7 & 6 & 5 & 4 & 3 \\
\hline \multirow[t]{2}{*}{3} & \multirow[t]{2}{*}{$\begin{array}{l}\text { Endurance } \\
\text { Test }\end{array}$} & $\begin{array}{c}\text { Running at a } \\
\text { distance of } 5000 \\
\text { meters (min) }\end{array}$ & $\mathrm{M}$ & 27.00 & 29.05 & 31.30 & 33.40 & 35.30 \\
\hline & & $\begin{array}{c}\text { Running at a } \\
\text { distance of } 2500 \\
\text { meters (min) }\end{array}$ & $\mathrm{W}$ & 12.40 & 13.30 & 14.20 & 15.10 & 16.00 \\
\hline \multirow[t]{2}{*}{4} & \multirow{2}{*}{$\begin{array}{l}\text { Test the } \\
\text { jumping }\end{array}$} & \multirow{2}{*}{$\begin{array}{l}\text { Long jump }(\mathrm{cm}) \\
\text { from the spot }\end{array}$} & $\mathrm{M}$ & 255 & 240 & 225 & 208 & 191 \\
\hline & & & $\mathrm{W}$ & 205 & 194 & 183 & 173 & 161 \\
\hline \multirow[t]{2}{*}{5} & \multirow{2}{*}{$\begin{array}{l}\text { Test for the } \\
\text { determination } \\
\text { of mobility in } \\
\text { the ankle } \\
\text { joints }\end{array}$} & \multirow[t]{2}{*}{ Points } & $\mathrm{M}$ & 10 & 8 & 6 & 4 & 2 \\
\hline & & & W & 10 & 8 & 6 & 4 & 2 \\
\hline \multirow[t]{2}{*}{6} & \multirow[b]{2}{*}{$\begin{array}{c}\text { Test for } \\
\text { determining } \\
\text { the flexibility } \\
\text { of the } \\
\text { vertebral } \\
\text { column }\end{array}$} & \multirow[t]{2}{*}{ Points } & $\mathrm{M}$ & 10 & 8 & 6 & 4 & 2 \\
\hline & & & W & 10 & 8 & 6 & 4 & 2 \\
\hline
\end{tabular}

\section{Results}

In order to improve the students of the study group we tested, we used a technique that included performing various physical exercises during the background sound of musical accompaniment. This, in turn, not only had a positive effect on the emotional and 
psychological state of the students, but also allowed them to use a personal approach to each student individually, taking into account the level of their physical fitness.

In our opinion, the composition of health-improving fitness classes should include the following types of loads: stretching, strength and aural load. Taking this into account, the classes that we conducted with students during physical education lessons were divided into three parts:

1. Warm-up. The goal of the workout was to increase heart rate and breathing speed up metabolism, warming the body, increasing the level of elasticity of muscles, tendons and ligaments students. The preparatory part began with the process of repeating and learning the basic movements and movements that are used in dance aerobics, such as "Marsh", "Step-Ter", "Step-Touch", "Cross", "V-Step", as well as knee lifts "Knee lift" and back flops "Leg Curl". Students were allowed to work with their hands as if they were walking or to fix them on their belts. The duration of the warm-up part was approximately 8-12 minutes.

2. The main part of the lesson. The main part of the training session was aimed at improving students ' coordination skills and learning new ligaments.

During the main part of the training, a constant aerobic load in the non-stop mode was used. This involved learning a series of small, repetitive combinations of movements, which consisted of a set of basic movements, which were supplemented by hand movements in the form of jerks and swings. During the main part of the lesson, we used an individual approach to each student, students with a lower level of physical fitness performed hand movements at a convenient pace for them.

In order to increase the level of aerobic exercise, students were replaced with some basic movements such as "Cha-Cha-Cha", "cross", "mambo", and step movements were combined with jumps with jumps "Jumping", leg swings "Kick", as well as running on the spot "Jog". More physically prepared students, in order to improve their physical form, had the opportunity to further increase the level of load by using dumbbells weighing from 1 to $2.5 \mathrm{~kg}$.

In the final part of the lesson, students performed stretching exercises for various muscle groups.

At the same time, the teacher conditionally divided the students into three subgroups according to their level of physical fitness:

1) Students with good physical fitness and coordination abilities had the opportunity to perform a bunch of exercises completely, and if desired, use additional weights.

2) Students with a weak level of physical fitness, but a good level of coordination abilities performed movements with a reduced amplitude of hand movement or without the use of rebounds. They could independently set the level of their load.

3) Students with poor coordination and a weak level of physical fitness performed only elementary movements with their legs and arms, trying to match their movements to the musical rhythm.

3. The final stage of the lesson. At the final stage of our classes, we conducted exercises for stretching, or "stretching". This took place within 6-8 minutes. This part of the lesson also provided for an individual approach to each student, depending on the level of his physical development. The task of stretching was to relieve the load on the muscles by stretching Due to the fact that the mobility of the joints and the elasticity of the ligaments are individual in each person, the stretching exercises were performed in such a way that when bending, students did not experience excessive load in the spine, as well as in the ankle and knee joints. If the student felt pain and discomfort during the tilt in front, then he could perform this exercise in a light version. He could just round his back and bend his knees a little. The correct performance of stretching exercises helped to improve the 
elasticity of the ligaments, muscles and tendons of the students, in addition to the normal state of the heart rate of the students.

If a person experienced discomfort or pain when leaning forward, then a light version of this exercise was recommended - slightly bend the knees and round the back. With the correct performance of this stretching exercise, the elasticity of the muscles, ligaments and tendons was increased, and the heart rate returned to normal.

A specific feature of music is that moods, experiences, and ideas are expressed through a harmonious combination of rhythmic sounds and tones. Using them, a person has the opportunity to convey their mood, as well as their feelings and emotions. Music affects not only the human attention, but also has a beneficial effect on the intellectual and creative abilities of a person. Music can help a person relax or give additional strength. According to $[8,9]$, classical music has a great energy potential, and is able to have a beneficial effect on the human body.

We hold the view that the rhythm and tempo of music have a stimulating effect on the desire to perform motor movements in unison. They can excite or calm the human nervous system, and therefore affect the overall physical condition of the student.

Fitness classes on a regular basis, in our opinion, contribute to improving the level of physical and mental performance. The effectiveness of fitness classes is largely dependent on the selected musical accompaniment.

According to [10], music encourages a person to have certain emotions and feelings that correlate with various forms of physical activity. Popular music compositions increase the level of human mood, increase concentration, and also give a charge of cheerfulness and energy.

We adhere to the point of view that for each type of wellness fitness, it is necessary to select the appropriate tempo and musical style. For example, for aerobics classes, a rhythmic musical accompaniment that can set the necessary tempo will be most effective. For training in gyms, in our opinion, the best option is rock music.

Since the musical tempo can have a great impact on the physical and mental state of a person, in our opinion, for physical exertion of a large level of intensity, the music tempo is about 105-135 beats per minute, and for pilates classes from 60 to 100 beats per minute. At the same time, we believe that when choosing a musical tempo, first of all, the state of physical fitness of the students should be taken into account.

At the end of the academic year, we once again tested the physical condition of the students, the results of which are presented in Table 2.

Therefore, based on the results of the study, we come to the conclusion that fitness classes during physical education classes contribute to the improvement of students ' physical qualities.

Table 2. Comparative results of testing the physical fitness of students of the test group at the beginning and end of the academic year.

\begin{tabular}{|c|c|c|c|c|c|}
\hline \multirow[t]{2}{*}{ № } & \multirow[t]{2}{*}{ Types of tests } & \multirow[t]{2}{*}{ Name of the standard } & \multirow{2}{*}{$\begin{array}{l}\text { gende } \\
\mathrm{r}\end{array}$} & \multicolumn{2}{|c|}{ Average score } \\
\hline & & & & $\begin{array}{c}\text { At the } \\
\text { beginning of } \\
\text { the school } \\
\text { year }\end{array}$ & $\begin{array}{l}\text { At the end of } \\
\text { the school } \\
\text { year }\end{array}$ \\
\hline \multirow[t]{2}{*}{1} & \multirow[t]{2}{*}{ Speed Test } & \multirow{2}{*}{$\begin{array}{l}\text { Running at a distance } \\
\text { of } 100 \text { meters }(\mathrm{sec} .) \\
\text { Running at a distance } \\
\text { of } 60 \text { meters (sec.) }\end{array}$} & $\mathrm{M}$ & 4,1 & 4,2 \\
\hline & & & $\mathrm{W}$ & 4,2 & 4,3 \\
\hline
\end{tabular}


Table 2. Continued

\begin{tabular}{|c|c|c|c|c|c|}
\hline \multirow{4}{*}{2} & \multirow{4}{*}{ Strength Test } & $\begin{array}{c}\text { Pull- } \\
\text { up on a high crossbar } \\
\text { (times) }\end{array}$ & \multirow{3}{*}{ M } & 4,3 & 4,4 \\
\hline & & $\begin{array}{l}\text { Push-up on the uneven } \\
\text { bars (times) }\end{array}$ & & 4,0 & 4,1 \\
\hline & & Bench press (kg) & & 3,8 & 4,1 \\
\hline & & $\begin{array}{l}\text { Flexion and extension } \\
\text { of the arms at the stop } \\
\text { lying down from the } \\
\text { gym bench (times) }\end{array}$ & W & 4,1 & 4,2 \\
\hline \multirow[t]{2}{*}{3} & \multirow[t]{2}{*}{ Endurance Test } & $\begin{array}{l}\text { Running at a distance } \\
\text { of } 5000 \text { meters (min) }\end{array}$ & $\mathrm{M}$ & 4,1 & 4,2 \\
\hline & & $\begin{array}{l}\text { Running at a distance } \\
\text { of } 2500 \text { meters (min) }\end{array}$ & $\mathrm{W}$ & 4,0 & 4,2 \\
\hline \multirow[t]{2}{*}{4} & \multirow[t]{2}{*}{ Test the jumping } & \multirow{2}{*}{$\begin{array}{l}\text { Long jump }(\mathrm{cm}) \text { from } \\
\text { the spot }\end{array}$} & $\mathrm{M}$ & 4,1 & 4,2 \\
\hline & & & $\mathrm{W}$ & 4,2 & 4,3 \\
\hline \multirow[t]{2}{*}{5} & \multirow{2}{*}{$\begin{array}{l}\text { Test for the } \\
\text { determination of } \\
\text { mobility in the ankle } \\
\text { joints }\end{array}$} & \multirow[t]{2}{*}{ Points } & $\mathrm{M}$ & 3,7 & 3,8 \\
\hline & & & W & 4,1 & 4,2 \\
\hline \multirow[t]{2}{*}{6} & \multirow{2}{*}{$\begin{array}{l}\text { Test for determining } \\
\text { the flexibility of the } \\
\text { vertebral column }\end{array}$} & \multirow[t]{2}{*}{ Points } & $\mathrm{M}$ & 4,1 & 4,1 \\
\hline & & & $\mathrm{W}$ & 4,1 & 4,2 \\
\hline
\end{tabular}

\section{Discussion}

In modern times, the concept of "fitness" has firmly entered the lives of many people who want to be in good physical shape. This can be achieved through regular and persistent training and an appropriate level of physical activity. The process of managing and organizing training work requires a well-thought-out preparation of training sessions for the teacher.

Due to the differences in the individual physiological characteristics of students and their level of physical fitness, different students learn different movements in fitness. In this regard, we believe that an individual approach to training based on the level of physical fitness of students will be optimal.

A musical composition that sounds during a fitness class can increase the mood of those involved, reduce the feeling of fatigue, liberates and promotes the performance of clear and rhythmic movements. Pleasant music helps students quickly recover their strength after physical or mental work.

At the same time, too long classes with increased intensity of physical activity can have a negative impact on the human body.

\section{Conclusions}

Based on our research, we came to the conclusion that the forms and types of fitness aerobics make it possible to apply an individual approach when choosing methods and means of physical education. The methodology developed by us in this work allows us to develop the optimal training option for students in accordance with their level of physical fitness.

With regular exercise fitness among students is the development of skeletal muscle, improving the functioning of the musculoskeletal system. As a result of regular exercise, 
students ' resistance to stressful situations increases, as well as the degree of adaptability to physical exertion.

In our opinion, an important contribution to the acquisition of the necessary knowledge about health can be made by the introduction of mandatory teaching of the valeology course in higher educational institutions. Problems that valeology studies late or early all people face throughout their lives. Therefore, the study of obtaining knowledge by students that contributes to the preservation and promotion of health should be a state, and not just a personal task.

\section{References}

1. Edward Martindale, Ann Devlin, Stuart Vyse, Perceptual and Motor Skills, 71, 1139 (1990)

2. Richard Weil, Diabetes self-management, 21(1), 76 (2004)

3. Benje Bailey, Gaming Law Review, 4, 339 (200)

4. Guilan Wang, Jie Shi, Miao Xin, The Role of College Sports in Humanities Education, 116 (2010)

5. Neil Laughlin, Journal of College and Character, 4 (2003)

6. N. Tubus, Injury-international Journal of The Care of The Injured, 13, 452 (1982)

7. Karolyn Tacha, Verneda Edwards, Susan Miller, Journal of Physical Education, Recreation \& Dance, 55, 61 (1984)

8. W. Yan, Y. Zhang, Agro Food Industry Hi-Tech, 28, 1642 (2017)

9. Laurence Holt, Thomas Pelham, Jason Holt, Sports, Fitness, and Dance Applications (2008)

10. Bin Xu, College Students' Health Education and College Sports Environment (2015)

11. Z. A. Wei, G. Z. Yin, L. Wan, and G. Z. Li, Environ, Earth Sci., 75 (2016) 